\title{
L'infant Pere d'Empúries i la tradició familiar: estampes en el setè centenari del seu naixement
}

\section{Lluís Cabré}

El llinatge català que va governar sense interrupció la Corona d'Aragó des del comte Ramon Berenguer IV fins al comte-rei Martíl (| |37-|4|0) és un exemple de longevitat. Els seus interessos culturals, implicats en la política, van acompanyar aquesta trajectòria, no fa gaire traçada per Anton M. Espadaler (200I) en un vigorós retrat de família. Dues paraules resumirien aquestes inclinacions: la història i el trobar.

De cap a cap d'aquest llarg període cultural, reis i membres de la Casa d'Aragó en les seves diverses branques van cultivar personalment la poesia de tradició occitana, van envoltar-se de trobadors i joglars, i, dit curt, van convertir l'art de trobar en una etiqueta de la cort: la poesia catalana medieval els deu gairebé tota la vida. Paral·lelament, després dels Gesta comitum Barcinonensium et regum Aragonum, iniciats a Ripoll en temps d'Alfons I i actualitzats posteriorment, els monarques catalans van dictar, escriure o promoure un singular conjunt historiogràfic marcat per la tradició familiar. Així, el semi-

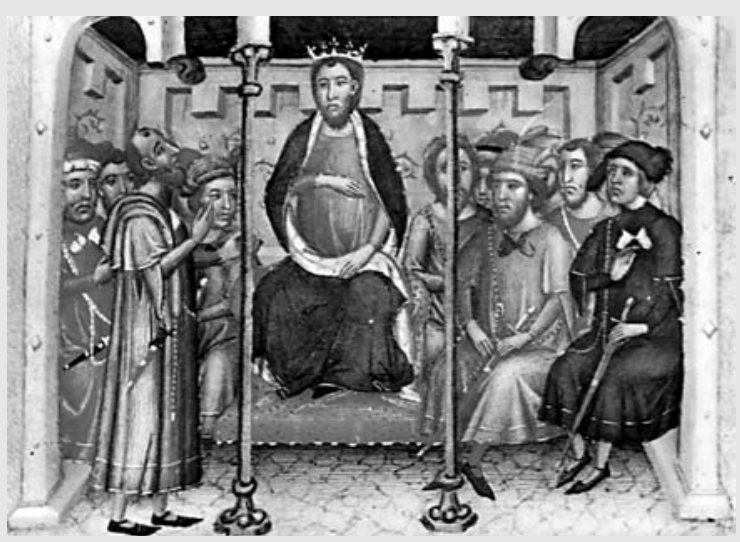

El rei Jaume II (|29|-|327), pare de l'infant Pere (miniatura del Llibre Verd). nal Llibre del rei En Jaume (I) inspiraria el Llibre del rei En Pere (II), el fill; Jaume II, el nét, en va encarregar una versió llatina, memorable; el rebesnét, Pere III, en va invocar l'obertura, per mitjà d'una cita de sant Jaume, al pròleg del Llibre que narra els «fets» del seu propi regnat. D'altra banda, per posar un sol exemple, Martí I va il·lustrar un cèlebre discurs a Perpinyà ( 1406) amb la llegenda del bon comte de Barcelona que deslliurà l'emperadriu d'Alemanya, pouant-la dels capítols prologals del Llibre de Pere II. L'anècdota ens ensenya que la passió per la crònica feia joc amb l'oratòria parlamentària i la retòrica epistolar. Al mateix interès, com anirem veient, pertanyen els tractats sobre el regiment de prínceps i textos afins.

En aquesta fotografia familiar hi ha una figura de pes que espera encara una monografia: l'infant Pere d'Aragó (| 305-8 |), vuitè fill de Jaume || i Blanca d'Anjou, germà d'Alfons III i oncle de Pere III. La seva intervenció en la cultura literària i la política civil i religiosa del seu temps és coneguda, però es troba a faltar una visió de conjunt - el retrat que sens dubte tindríem si hagués arribat a regnar o s'haguessin conservat les seves poesies.' És possible retallar alguns moments en què l'infant domina l'escena i mirar de destacar-ne algun

\footnotetext{
I. Quan aquest treball ja estava lliurat, he pogut llegir, per amabilitat de l'autora, un estudi que supera de llarg tots els anteriors, particularment pel que fa a la producció política de l'infant (Beauchamp 2005, amb recull bibliogràfic); només l'he pogut aprofitar parcialment. Abans d'aquesta contribució, l'aspecte més estudiat era el seu vessant de visionari. Vegeu la sèrie (interrompuda) d'articles d'Alfons Maria de Barcelona (19/3-15) i el volum de Josep Pou i Martí de 1930, que cito segons la reimpressió amb pròleg d'Albert Hauf (Pou 1996: 46I-56I); vegeu les Pp. 62-64, 72 , i $105-110$ de la introducció. McVaugh (1986) va confirmar que Pere era el vuitè fill i no el setè (com s'ha divulgat erròniament). Per a la data de naixement, vegeu més avall, n. 3.
} 
enfocament poc conegut. Però, ara que fa set-cents anys del seu naixement, potser s'ha de dir en veu alta que, sense un itinerari complet i un estudi històric que expliqui la seva actuació política d'acord amb els seus interessos, i no com a actor secundari, aquests apunts seran, inevitablement, estampes.

\section{Visions}

El rei Jaume II va dotar el seu fill Pere, tot just emancipat, amb el comtat de Ribagorça en 1322, i amb diverses senyories valencianes, incloent-hi Gandia i, després d'una permuta, Dénia (1 323). Des de 1325, i malgrat l'oposició papal, Pere va exercir el govern del comtat d'Empúries, bescanviat en 134 I pel de les Muntanyes de Prades, propietat del seu germà petit Ramon Berenguer. Després de molts tractes fracassats, el I331 es va casar fastuosament a Castelló d'Empúries amb Joana de Foix. Entre les moltes actuacions que el situen en primer rengle de la història, potser destaca la decisiva intervenció en l'annexió de Mallorca. ${ }^{2}$

La seva notable trajectòria política va arribar a un tombant. El novembre de 1358, Pere, assessor diplomàtic de tres monarques — pare, germà i nebotva renunciar als seus títols per vestir l'hàbit franciscà. Segons ell mateix relata, la decisió va ser fruit d'una visió - la primera d'un llarg expedient - al castell de Falset. Sant Lluís, bisbe de Tolosa, li va mostrar tots els «de nostre llinatge et sots hàbit de sant Francesc e de santa Clara» que es trobaven a la glòria. ${ }^{3}$ Devia veurehi, entre d'altres, a santa Isabel de Portugal (filla de Pere II) o a Alfons II, enterrat amb l'hàbit de burell al con-

2. Hi ha semblances històriques de l'infant als treballs citats a la nota anterior i també a Valls i Taberner (1926) i a Casas Homs (1969). Vegeu també Martínez Ferrando (1948: I58-169) i Sobrequés (1957: 132-140).

3. Vegeu Pou (1996: 509); regularitzo. És aquí on afirma: «dilluns a XII de novembre [...] io reebí lo sant hàbit de mossèn sent Francesc l'any de la Incarnació de Jesucrist mil.CCC.LVIII et en l'any de mi dit frare Pere LIII anysı. Vegeu també McVaugh (1986: I4-I5), que interpreta que tenia entre 52 i 53 anys i conclou que hauria nascut entre novembre de 1305 i novembre de 1306 . El text sembla dir que feia 53 anys entre l'Encarnació ( 25 de març) de 1358 i la de 1359 , és a dir, que aquell era el seu 53è any. Però el relat és molt posterior i, com em fa notar Jaume Riera, l'infant devia recordar que el novembre de 1358 tenia 53 anys; tirant enrera, el novembre de 1306 ja n'havia fet un i, doncs, devia haver nascut abans del novembre de 1305, entre el 25 de març i el 12 de novembre d'aquest any si volem apurar el document. vent franciscà de Barcelona (Alfons Maria de BarceIona 1913-15: | |, |32-133). Però la tradició familiar era doble: sant Lluís (bisbe i sant) era el seu oncle Lluís d'Anjou, germà de Robert d'Anjou, rei de Nàpols, i l'un i l'altre, infants, havien passat uns anys importants a Catalunya com a ostatges (1288-95) sota la influència franciscana. Molt més endavant, el rei Robert va facilitar en un moment crucial la imposició de l'infant Pere com a tutor de Pere $111 .{ }^{4}$ Aquest fil familiar, revelat en la visió, no s'ha de menystenir: devia abonar la relació amb el papat molt abans que Pere ingressés el 12 de novembre al convent de framenors de Barcelona, al capdavall de la Rambla.

Ja menoret, Pere d'Aragó va guanyar-se justa fama de visionari apocalíptic. La primera sèrie de revelacions ( 1365 ) el va portar a Avinyó: volia convèncer Urbà V que tornés a Roma, i així va ser ( 1367 ) durant tres anys. D'aquest episodi en queda un report del seu confessor Ramon de Sarrià, la declaració al papa i el memoràndum posterior en defensa de l'autenticitat de les visions. Tot en llatí, excepte la transcripció del moll de

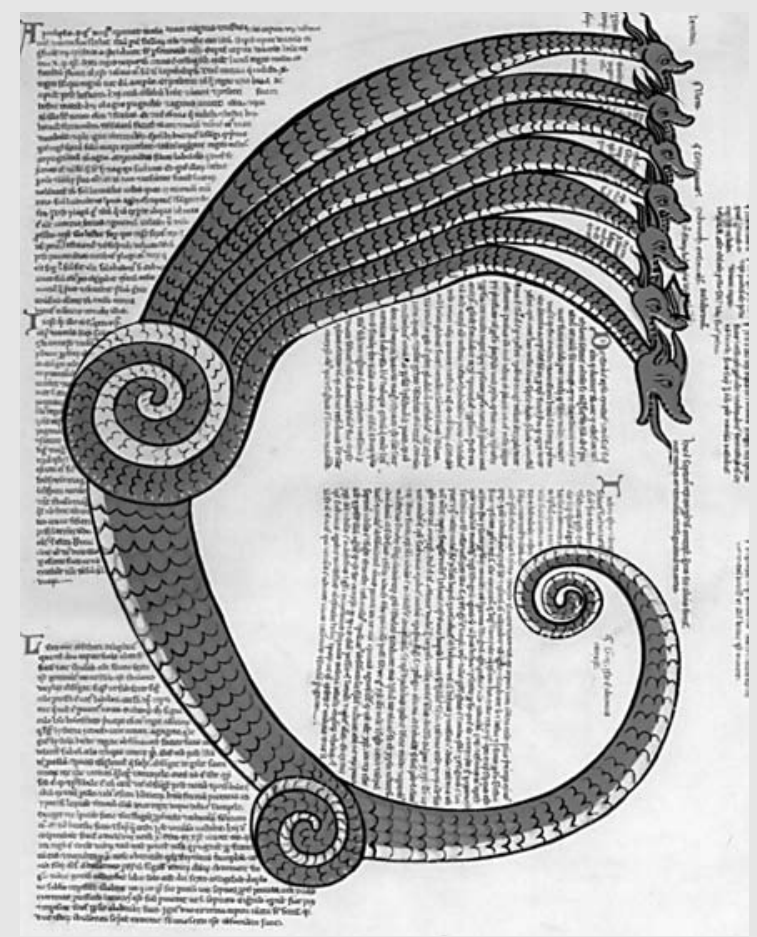

El drac de set caps al Liber figurarum del visionari Gioacchino da Fiore (s. XIII).

4. Pou (1996: 39-43 i 502). En la pugna entre Robert de Nàpols i Frederic de Sicília, l'infant mantenia bona relació amb el papa (cf. també 492). 
la revelació: «per ço [l'infant] fa la dita declaració en romanç, en sa pròpia llengua, que pusca mills expressar sens mençònega ['mentida'] ço que per Aquell qui és veritat li fou revelat». L'àngel i els apòstols no parlaven en català, però fra Pere tal volta els transliterava així. En aquest text, tanmateix, el llatí s'hi transparenta, fins en els moments més reeixits, com ara en l'habitual lament pel «captiveri babilònic» de la cúria romana:

los santuaris de Roma no tan solament són romases deserts de l'especial bisbe llur e de los presidents altres d'aquella, mas són fets alcuns bells e dels majors habitacles e corrals d'ovelles e de cabres, e, per consegüent, ne cases de Déu ne d'oracion, mas femer e llocs de sutzura e d'immundícia. ${ }^{5}$

Les visions no es van interrompre. En les més rellevants, ja en temps del Cisma (1378), l'infant, devot del papa romà Urbà VI, va trobar-se amb la cautela de Pere III i l'escepticisme radical de l'infant Joan (futur Joan I), partidari del papa avinyonès Climent VII. Per aquesta raó, les revelacions de 1379 no van tenir conseqüències tan plàcides com les de 1365. Un comitè de teòlegs les va examinar, amb diagnòstic dividit, com era d'esperar. ${ }^{6}$ El tracte deferent no impedeix observar que l'urbanisme encès havia convertit l'infant en un problema polític, sobretot després que el rei de Castella es decantés a favor d'Avinyó. En una darrera visió, a Medina del Campo, va rebre el mandat d'adreçarse a Roma. Tement per la seva seguretat, l'infant va demanar a Pere III un salconduit.? El rei el va deixar a

\section{Alfons Maria de Barcelona (19|3-15: 14, 206 i 208); regularitzo. També conservem en català una Exposició, plenament joaquimis- ta, que presenta Enrique de Trastámara, vencedor del Cruel, com el futur rei de Jerusalem: Pou (1996: 530-535). Vegeu Bohigas (1923), on es data el text el 1373, i Lee, Reeves \& Silano (1989: 8I-85), que l'emplaça en I377. Aquesta és la data correcta: al text s'esmenta la mort del Príncep Negre (I376) i s'hi afirma «de LXXVII, que ara comptam, tro a XC [ie. 1390, any de la des- trucció dels infidels, segons Gioacchino da Fiore] ha XIII anys».}

6. Pou (1996:535-56I). El provincial fra Tomàs Alsina, clementista i adversari de l'infant Pere, les va considerar «sompnia uel uehementes cogitationes», i fra Francesc Rafart, confessor de l'infant Joan, es va limitar a dir «quod nichil uolebat super ipsis dicere nec curabat in aliquo de eiusdem».

7. Pou (1996: 522-525); regularitzo. El rei se sorprèn de la petició («bé que no fos necessari, com entenam e vullam que dins nostra senyoria vós tota vegada [...] puixats [...] ésser e estar salvament e segura sens salconduit e altre guiatge») i prega l'infant que el vagi a veure a Saragossa («car nós volem parlar llargament ab vós de diversos afers»).
Barcelona, en mans del seu uixer d'armes, Jaume March, segurament perquè era persona de confiança de l'infant — la família March l'havia servit des d'antic, com veurem més avall. A resultes d'aquest darrer viatge a Roma, Pere d'Aragó va morir a Pisa el 4 de novembre de 1381. Cinc anys després, les seves despulles es van traslladar a València, al convent de Sant Francesc, amb càrrec al pressupost del Consell de la ciutat (Valls i Taberner 1926: 37, 285). Havia mort amb fama de sant i venerat pel seu nebot (Pou 1996: 525 i Gubern 1955: 41 ). Alguns capítols del Segon de Francesc Eiximenis semblen indicar, però, que la interpretació política va perseguir fins al final les seves visions. ${ }^{8}$

\section{Poesia}

El cambrer Gil López de Mestre va ser el primer instructor de l'infant (13|4), al qual hem de suposar les lletres - la gramàtica - adquirides amb manuals com el Doctrinale. ${ }^{9}$ Deu anys després, el jove Pere ja tenia reputació de persona eloqüent. El papa Joan XXII, el mateix que l'amenaçaria amb el càstig diví amb motiu d'una malaltia (i de les pretensions de l'infant al comtat d'Empúries), reconeixia la seva precocitat en una carta de 1324 adreçada a Jaume II: «que l'estimat fill, el noble Pere, infant vostre, comte de Ribagorça, adolescent i d'edat tan tendra, abunda en tal discreció i eloqüència i gràcia que qualssevol afers que la vostra excel·lència li encomanés sabria exposar-los amb paraules tan ben disposades ('tam disserte') com prudent en fóra l'execució» (Pou 1996: 475). Part d'aquesta eloqüència es va destinar a l'art de trobar.

El mateix any de la carta papal, Raimon de Cornet va dedicar a Pere d'Aragó un Doctrinal de trobar, on l'anomena «valen / e de trobar saben / e gen enamorat»>. ${ }^{10} \mathrm{El}$ dia de Tots Sants de 134I, el rossellonès Joan de Castellnou, cortesà de Pere III i un dels set mantenidors del concurs poètic de Tolosa de Llenguadoc, escrivint en nom de l'ortodòxia de les Leys tolosanes, li'n va oferir la rèplica (Casas Homs 1969: 203).

8. Vegeu Hauf (1990: 65 i I I8), matisat a la seva introducció a Pou (1996: 105-I10).

9. Rubió i Lluch (1921: 21 ) i Martínez Ferrando (1948: 45-46). Per a la cultura llibresca de l'infant, vegeu ara Beauchamp (2005).

10. Casas Homs (1969: 201). El millor resum d'aquesta faceta de l'infant es troba a Badia (1983: 24-29). 


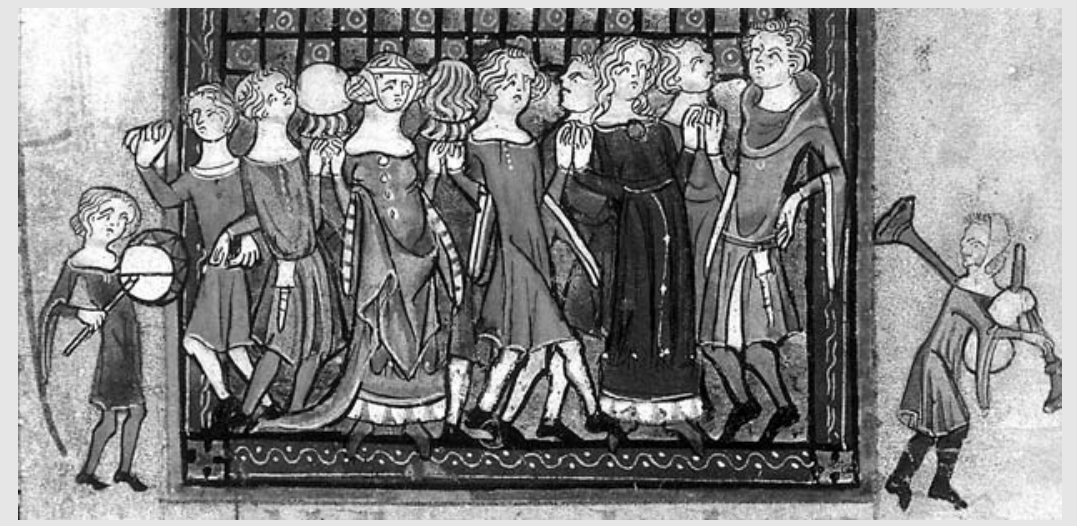

llers, e nosaltres, ciutadans», diu Muntaner. En aquesta escenografia hi apareixen a continuació diversos joglars. Ramasset canta un siventès «que el senyor infant En Pere hac fet a honor del dit senyor rei»s, el contingut del qual explicava el significat de la corona, el pom i la verga, i els deures reials que se'n seguien. Muntaner ho glossa: la doctrina de l'origen diví de la monarquia, la justícia del batlle secular i les virtuts necessàries del gover-

Dansa cortesana, representada en un manuscrit del Roman de la Rose (British Library, Londres).

L'infant mantenia la tradició del trobar familiar, o, millor dit, l'acreixia considerablement. En un passatge celebrat de la seva Crònica, Ramon Muntaner detalla les festes de la coronació d'Alfons III el I328.'

Les cerimònies van tenir lloc a Saragossa, a l'església de Sant Salvador i al palau de l'Aljaferia, per Pasqua. El context litúrgic, volgut, permet a Muntaner tancar el relat messiànic comparant la coronació d'un nou rei amb la redempció: el Casal d'Aragó, nascut amb Jaume I de manera prodigiosa, com el Salvador, ressuscita amb el nou rei Alfons III (Vàrvaro 1984). L'ocasió simbòlica demana el detall, i Muntaner s'hi va esplaiar. Podem assistir, des de la llotja de lector, als actes religiosos, als rituals cavallerescos i al banquet. L'infant Pere hi oficiava en qualitat de majordom. Hi ha qui ha interpretat que volia fer-se perdonar la reivindicació de la Corona pocs anys abans, si el seu germà Alfons moria a la campanya de Sardenya (1 323-24). També es pot pensar que Pere tendia al fast-les despeses del seu casament el van mig arruinar. El cas és que, al banquet de 1328, l'etiqueta poètica actuava quasi dramàticament. L'infant va entrar cantant i ballant una dansa de pròpia creació («novella»), i, plat per plat, fins a deu, va anar canviant de vestits, regalant-los als joglars en senyal de largueza, i entonant les cobles d'una nova dansa, mentre els cambrers «responien-li», és a dir, cantaven el respos o refrany. Vet aquí, doncs, deu danses festives perdudes, que confirmen l'elogi «de trobar saben / e gen enamorat». En acabat l'àpat, el rei va seure al tron enlairat, amb els atributs del poder, i la societat es va distribuir jeràrquicament als seus peus: «nobles, cava-

II. Són els caps. 293-298 de la Crònica de Ramon Muntaner (Casacuberta 1927-52: IX, 7-28). nant, això és, veritat, justícia i misericòrdia. Després entra Comí per interpretar una cançó de l'infant. Finalment, Novellet va dir «en parlant» set-cents versos, també obra del majordom, és a dir, unes noves rimades. Les dues últimes composicions tractaven del «regiment que el dit senyor rei deu fer a ordinació de la sua cort e de tots los seus oficials, així en la dita cort sua, com per totes les altres províncies».

Els joglars eren homes de baixa condició (com denoten els sobrenoms i l'ús del diminutiu), valorats per l'excel·lència de la interpretació —entenguem que la canso devia ser de lluïment i per això, diu el cronista, l'infant l'havia encarregada a en Comí, el qui «can-

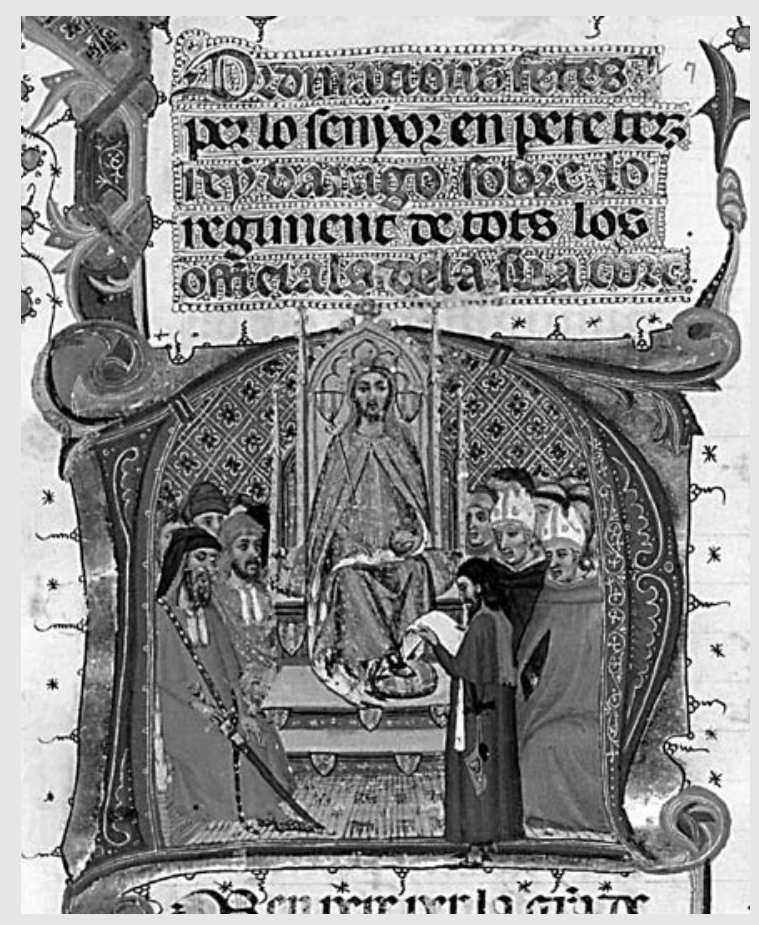

Pere el Cerimoniós, segons una miniatura de les seves Ordinacions (segle XIV, Biblioteca Nacional, París). 
ta mills de Catalunya», i que Novellet era l'especialista en recitar noves. La composició del vers (i de la música en el cas de les deu danses i la cançó) era de l'infant: si s'hagués conservat, aquesta producció el convertiria en el trobador català més conspicu de la primera meitat del segle XIV, i en el músic profà de sang reial més notable. Tot plegat, interpretacions, coreografia i escenificació, ens fan pensar en un acte molt elaborat, que possiblement va deixar rastre en la memòria familiar. Diria que Pere III pretenia emular-ne el fast a la seva pròpia coronació a Saragossa (havia de ser per Pasqua florida però es va retardar una mica), precisament quan els prohoms catalans (infant Pere inclòs) li havien girat l'esquena. ${ }^{12}$ D'altra banda, la festa és un testimoni del costum de remarcar el simbolisme polític d'una coronació. En aquest sentit, va bé comparar el sirventès de l'infant amb el protocolari discurs de l'arquebisbe de Saragossa en resposta al de Martí I a

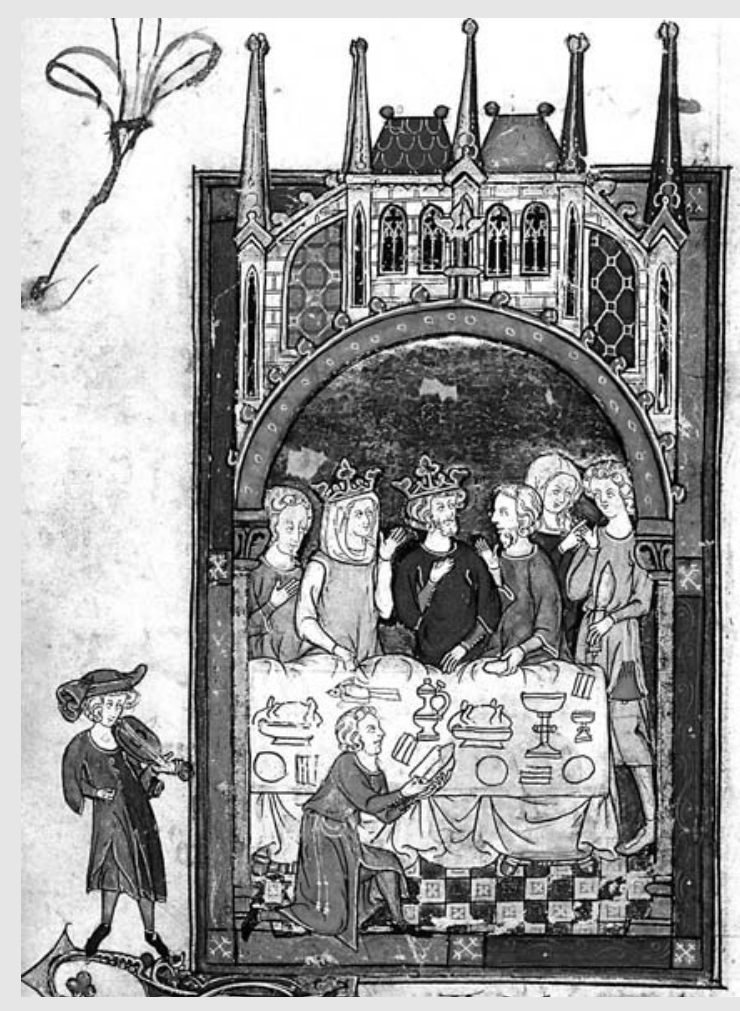

Representació d'un banquet cortesà amb acompanyament musical: aquí els reis són Artús i Ginebra (British Library, Londres).

\footnotetext{
12. Vegeu la descripció de la coronació de 1328 i de la pròpia a la seva crònica (I 37-39, Cortadellas 1995: 47-48 i II 6-16, Cortadellas 1995: 63-67). Vegeu també la plana 6 del pròleg de Hillgarth a Cortadellas (1995). Des d'ara cito la Crònica segons aquesta edició, amb modernització gràfica, indicant només capítol i secció. Per a l'anotació, Hillgarth (1980).
}

les corts de 1398 (Cátedra 1985-86: 43-47). L'arquebisbe hi glossa els atributs del poder reial d'acord amb la tradició cerimoniosa que coneixem. Escrivia Muntaner, per exemple, «el pom significa que així con ell té lo pom en la sua man, que los seus regnes té en la mà e en lo poder seu», i repetia l'arquebisbe: «El pomo significa los pueblos que el rey tiene en la mano de su jurdicción»».

L'escena brillant de 1328 no pot ser un fet aillat. Més aviat sembla un fragment d'una activitat cortesana que sovint només coneixem per referències, cas de les peces amoroses que Pere III confessa haver escrit de jove; per això té tant valor l'anomenat Cançoneret de Ripoll. ${ }^{13}$ Copiat en un plec, ara incomplet, per mà d'un clericus (les rúbriques són en llati) en el segon quart del segle XIV, el Cançoneret és un testimoni antic de la poesia catalana post-trobadoresca, o sigui, de la poesia occitana tal com es va mantenir en el pas al Tres-cents: ja dialectalitzada (val a dir catalanitzada) però molt fidel encara a la llengua poètica mare; amb una forta influència de Cerverí de Girona (el trobador per excel·lència de la cort reial a finals del segle XIII); i molt propensa a recollir tendències locals. El Cançoneret s'ha conservat per atzar, una mica com un fòssil d'una època en què les poesies autòctones encara no es recollien en cançoners amb finalitat memorable — per això hem perdut, contra tota expectativa, la producció de l'infant o els primers versos del seu nebot. El contingut ara sembla valuosíssim, però el continent és de factura ben pobra.

És significatiu que el plec conservat s'obri amb les Regles de trobar de Jofre de Foixà, seguides de dos tractadets poètics que les complementen i s'allargassen en les rúbriques a les poesies posteriors. Tot plegat demostra un interès per la preceptiva, i una mica d'escola: la voluntat d'obrir un marc autòcton amb un tractat ofert a Jaume, rei de Sicília, això és, el pare de l'infant Pere, després Jaume II. En els tractadets hi ha més simpaties locals. S'hi precisa, per exemple, que el sirventès serveix per tractar «alscuns fets assenyalats», entre els quals «aveniment de rei» (com hem vist a les festes de la Coronació), i es parla de les «cobles» com un gènere per debatre, «així com moltes que tot die·s fan» (i que s'han perdut, és clar). ${ }^{14}$ L'accés del compilador al

\footnotetext{
13. Vegeu l'excel·lent edició de Badia (1983). Per al rei Pere, vegeu
} Riquer (1964:535).

14. Marshall (1972: 10I). Vegeu una mostra del gènere a Josep Pujol (I99I: esp. 52-53). 
cercle de poetes pròxims a l'infant es constata en una nota en llatí on s'esmenta a Dalmau de Castellnou com a autor (o destinatari) de la resposta (perduda) a la dansa «Dompna, de mi merce us prenya». ${ }^{15}$ Aquest Dalmau de Castellnou deu ser el mateix que l'infant va adobar a cavaller en les festes repetidament esmentades (Badia 1983: 30-32). Allí, les poesies que interpretava el majordom, segurament de tema amorós, eren danses, i aquest és el gènere més representat en els tractadets i l'antologia subsegüent: una preferència d'època explicable si pensem en el caràcter festiu d'aquests actes cortesans.

Tota aquesta activitat, coneguda com aquell qui diu arqueològicament, és la que sens dubte es va acabar el 1358. Ara bé, fóra enganyós dividir massa taxativament la vida de Pere d'Aragó en un abans i un després de l'ingrés a l'orde, en un abans trobadoresc i secular i un després visionari i espiritualista. Si ho fem, $\mathrm{crec}$, alguna faceta de la seva figura se'ns escapa. Conscient de la seva posició en la línia de descendència, Pere d'Aragó, com ja s'ha dit, va intentar guanyar la successió a la Corona quan el seu germà Alfons era a Sardenya (1 323-24). La mateixa consciència es retroba quan insisteix en els drets familiars al regne en 1347 (Pou 1996: 505, n. 104). Això és realpolitik, més enllà de la imatge de saviesa recollida per la historiografia. I realpolitik sembla el fet que, ja franciscà i lliurat a les seves visions, Pere d'Aragó seguís assistint el seu nebot Pere III al camp i a la cúria. Convé recordar que proveïa el rei de tropes encara el maig de 1364, i aquestes intervencions les feia, segons Pere III, «estant sots religió de l'hàbit de sant Francesc» (Crònica, VI, 40). ${ }^{16}$ D'altra banda, les visions de 1365, exposades a Avinyó, no li van impedir aprofitar l'estada per facilitar la contractació (per part de Pere III) de les Companyies Blanques de Bertrand du Gues-

15. La responsiva començava «Senyer, valor no. $m$ ensenya» i estava copiada al darrer foli, avui perdut. Com anota amb prudència Badia (I 983: 2 II), la nota conté un relatiu ambigu: Dalmau també podria ser l'autor de «Dompna». En aquest cas, crec, la nota sorprendria una mica: bastava atribuir la peça a Dalmau a la rúbrica. «Dompna» és una petició d’amor a una «cosina» en posició de senhal (Badia 1983: 208); la presumpció més econòmica fa pensar que l'autor realment requeria d'amors una cosina. El debat hauria agradat a l'infant, que va intentar, sense èxit, casar-se amb la seva cosina Constança, i així ho va jurar públicament en I329 (Pou 1996: 483-486).

16. Sánchez-Cutillas (1967: 35-36). Per a la participació política de fra Pere, vegeu, per exemple, Tasis i Marca (1957 : 69 i 7677) i Abadal (1987: 24I). clin, ni per obtenir una subvenció pontifícia notable (Crònica, VI, 57). Per comanda papal, encara, va intervenir en la disputa sobre Xipre derivada de l'assassinat de Pere de Lusignan, casat amb Elionor, filla de l'infant (Pou 1996: 5 I2-5 I3). A la meva manera de veure, les seves inclinacions culturals també van deixar petja més enllà de 1358. Recapitulem i vegem-ne algun exemple.

\section{Casa}

Convertit en un senyor feudal de gran envergadura, gràcies al seu pare, i en senescal d'Alfons III i canceller de Pere III, l'infant va acumular patrimoni i influència. Part del primer, el va cedir al seu primogènit Alfons, titular del nou comtat de Dénia des de 1356 -així orientava el fill als dominis valencians (amb el temps, aquest Alfons, dit el Duc Vell, va esdevenir comte de Ribagorça el 1358, marquès de Villena el 1366 i duc de Gandia el 1399, per concessió especial de Martí l). En paral·lel, i sota la protecció reial, prosperava la família March.

Un Pere March dit familiarment «lo Prohom» va adquirir el 1323 el castell d'Eramprunyà — les ruïnes romàntiques del qual encara presideixen, en un turó prop de la carretera de Begues a Gavà, uns dominis que s'estenien fins a la platja de Castelldefels, on, a l'època, encara hi arribava algun dofí. També tenia

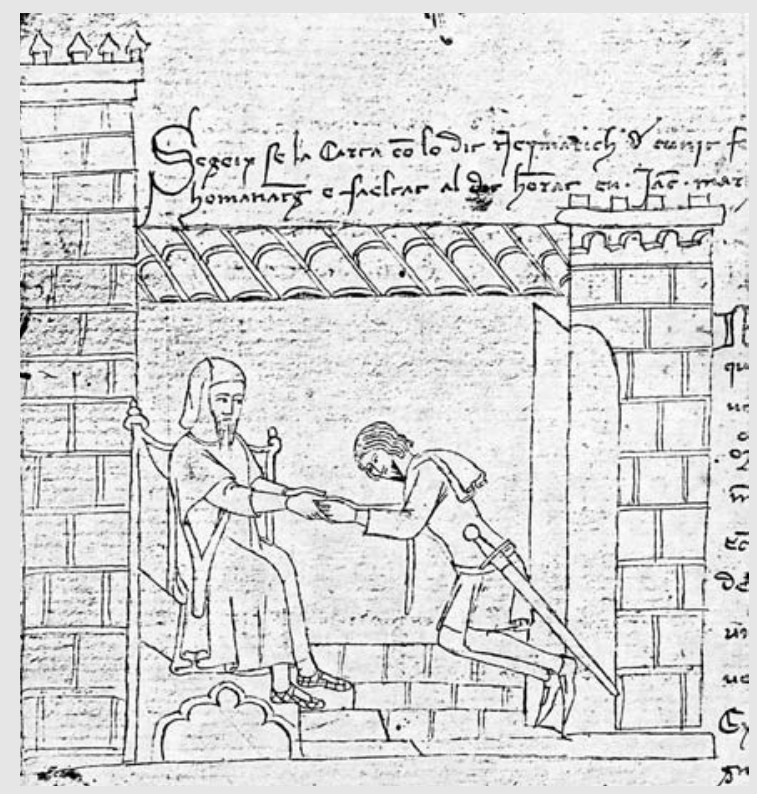

Eimeric de Cunit ret homenatge, per la casa de La Sentiu, a Jaume March, pare del poeta, el I35I (Llibre de la baronia). 
possessions a València, de manera que el Prohom va assignar aquest destí al seu segon fill, ben bé amb la mateixa distribució patrimonial que acabem de veure. Es deia Jaume, nom que va transmetre al seu fill el poeta Jaume March —el lector ja deu haver observat la imposició de noms reials. Jaume pare va tenir sort: I'hereu del seu germà gran era sord-mut (germà i nebot es deien Pere, és clar) i, amb la probable influència de l'infant, va guanyar-li un plet pel feu d'Eramprunyà i es va traslladar a Barcelona ( I35 I). Aquest Jaume s'havia casat en segones noces amb una Esplugues —a l'alqueria de N'Esplugues encara posava el rei Pere en 1364 (Crònica,VI, 44) — i havia estat fidel a la monarquia, i a l'infant en particular, en temps de la revolta valenciana de la Unió. Va cobrar els serveis, i amb l'escreix: en 1360, Pere III va adobar-lo a cavaller, en presència del protector, fra Pere d'Aragó, com consta en un preciós relat del llibre de familia dels March. Doncs bé, aquest Jaume March va seguir el costum que hem anat veient: va destinar Jaume, el poeta, als dominis catalans i a la cort de Pere III, mentre encaminava el següent fill cap a les terres de València. Aquest fill era Pere March, també poeta i pare d'Ausiàs March. ${ }^{17}$

M'he entretingut en aquests detalls per il/lustrar algunes pràctiques d'adhesió a la monarquia. El que compta, culturalment parlant, és que Pere March, el

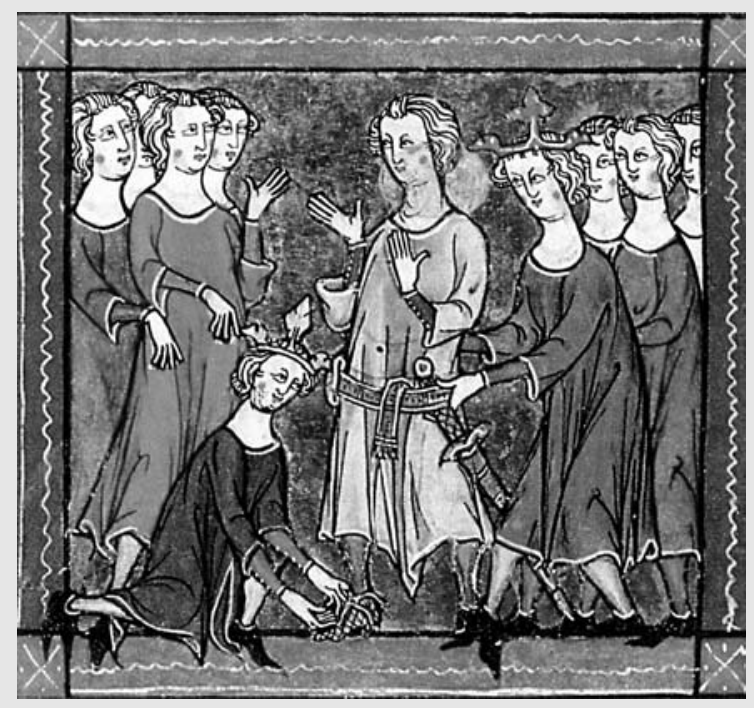

Cerimònia de l'adobament d'un cavaller (British Library, Londres).

17. Per a l'ascensió de la família March i la trajectòria de Jaume i Pere, vegeu les edicions de les seves obres a càrrec de Pujol (1994) i Cabré (1993); del segon extrec totes les cites poètiques. poeta, va ingressar de ben jove al servei d'Alfons, fill de l'infant. Pere March (ca. |337- |4 |3) consta el I 365 en la nòmina de les tropes (catalanes, notem-ho) del comte de Dénia, en temps de guerra amb Castella, però sense dubte aquesta data ha de recular almenys a 1357 , quan l'infant actuava de capità general i el comte el secundava en territori valencià - els mèrits guerrers de Jaume i Pere March ja s'al·ludeixen en l'adobament a cavaller del pare (1360). I potser hem de tirar més enrera. En un vers del Compte final, adreçat a Alfons, Pere March diu: «ab vós me sui criats». És ben possible, doncs, que abans de la guerra Pere March formés part de la casa de l'infant Pere, la que recorda el cardenal Jaume d'Aragó, el seu tercer fill, adreçant-se als consellers de Barcelona en 1395 :

\section{E com nós siam certs que la vostra noble ciutat entén més en lo bon regiment de la cosa públi- ca e familiar que altra ciutat, que nós sapiam, tant que espill de gran exempli pot ésser dita (a la qual ciutat vostra, nós nos tenim per molt tenguts e obligats, per la gran amor que hac al senyor infant En Pere, pare nostre, e a nós, qui estant fadrí nos nodrim aquí, faent-nos moltes honors e plaers), havem acordat de trametre-us lo dit Valeri arro- mançat. (Miquel i Planas 19|4: 3-4)}

Jaume March pare es va traslladar en I 35 I, quan Pere tenia vora catorze anys. Si aquest va viure a Barcelona al costat d'Alfons (es portaven uns cinc anys), fa ple sentit que, en 1413, Alfons el Jove, el nét de l'infant, fes constar que Pere March li havia «recitat en generalitat los bons, lleials e memorables serveis per vós incessantment en los dits temps fets als senyors infant En Pere, nostre avi, al dit senyor duc, nostre pare, de lloable memòria, e a nós»».

Pere March va esdevenir el procurador general d'Alfons, de la mateixa manera que l'infant havia estat el braç dret del rei Pere. Si se'm permet arriscar-ho, carrera i resultat literari semblen en part una conseqüència de les orientacions del seu primer senyor. Els versos de Pere March demostren coneixement de trobadors clàssics i de Cerverí de Girona, un bon domini de la retòrica i una base llatina; la seva dedicació, sobretot, exhibeix un model conegut: sirventesos de regimine principum i un text honorífic en noves rimades per a Alfons sobre el miles Christi (l'Arnès del cavaIler), mig cavalleresc mig eclesiàstic, que es diria com- 
post per a una celebració. Aquest model dóna compte d'un vers enverinat del Compte final: a Alfons, diu el seu procurador general, li convé no oblidar els vells servidors, els que vénen «del temps de vostre paire».

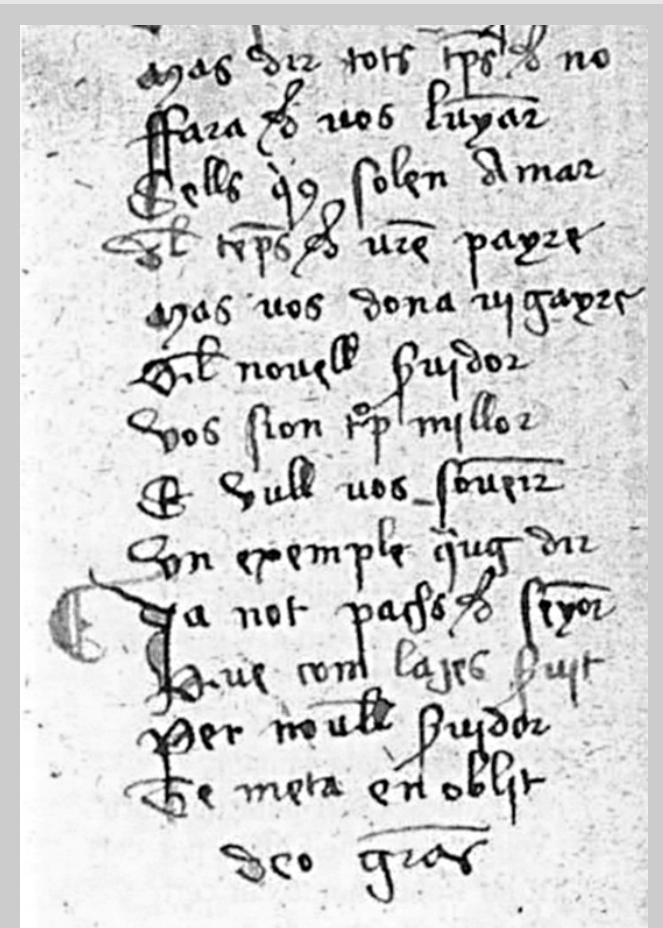

Detall del f. 20 v del Cançoner Estanislau Aguiló (Societat Arqueològica Lul.liana, Palma).

Aquesta és l'única còpia conservada del Compte final de Pere March, adreçat a Alfons d'Aragó. Els últims versos diuen:

Mas dir totstemps de no

ffarà de vós lunyar cells qui us solen amar del temps de vostre payre, mas vos dóna vigayre que $/$ novell servidor vos síon trop millor. E vull-vos sovenir un exemple qu'aug dir: "Ja no•t pachs de senyor que, com l'ajes servit, per novell servidor te meta en oblits. (v. 82-94, Cabré 1993: 180)

L'al·lusió a «vostre paire» ho és a l'infant Pere. El proverbi final és de Cerverí de Girona.
No sé si l'encerto atribuint a Pere March alguna herència literària de l'infant. No hi ha dubte, però, que en 1328 el jove Pere d'Aragó coneixia els fonaments dels tractats de regiment polític. Passades les danses festives, les altres composicions de la Coronació dibuixen una estructura doctrinal: el sirventès parla del princeps i les seves virtuts; la cançó i les noves, de la casa i l'estat («oficials» de la cort i les «altres províncies»). La ideologia subjacent, agustiniana i feudal, reapareix en un Tractatus de l'infant (que tractaré amb més detall al següent epígraf). A la mateixa tendència pertany, per exemple, el sirventès «Tots gran senyors qui bé vol avenir» de Pere March, amb la seva insistència en l'origen de la monarquia («e com entrec en lo món senyoria», v. 13), el valor dels consellers i oficials ( $v$. 17-24, 41-48) i la virtut de la institució cavalleresca («e mantenir tostemps cavalleria», v. 54). Potser tenen intenció els versos que exigeixen la col·laboració amb els barons en els afers d'estat («car ab los grans cové els grans faits obrar», v. 50), si no es vol arribar a la revolta. És un punt sensible que l'infant recordava a Pere III en exposar-li les sis condicions d'una guerra justa: convé consultar, particularment, els magnats («maxime magnorum et potentiorum regni suil») abans d'empendre la guerra, com mostren Isidor i els «exemples dels antics»». ${ }^{18}$

Amb la seva antiga inclinació per la literatura política, l'infant va ser una baula important en la cadena familiar. Potser no és atzar que el seu fill Alfons, ell mateix autor d'una epístola moral de regiment domèstic, urgís Francesc Eiximenis a enllestir el Dotzè del crestià o Regiment de prínceps e comunitats, o que rebés la dedicatòria de l'Escipió e Aníbal d'Antoni Canals, on pretesament s'adaptava al gust de la cavalleria i la moral de predicador un clàssic com Tit Livi (de fet, era l'Africa de Petrarca), estimat pels reis catalans des dels temps de Jaume II. ${ }^{19} \bigcirc$ que el cardenal Jaume promocionés la versió dels Facta et dicta memorabilia de Valeri Màxim a càrrec de Canals, un seu protegit que va ocupar la càtedra de teologia a la Seu de València, que va exercir idèntica funció com a lector a la cort de Martí l i que probablement va assesso-

18.Valls i Taberner (1926: I I5- | 16); per al principi jurídic de fons, Hauf (1990: I 19). Des d'ara citaré el Tractatus indicant-ne només el capítol.

19. És possible que el rei l'obtingués en I322: Martí de Barcelona (1990-91: 92, 423). Per a l'obra de Canals i la valoració de Livi, vegeu Rico (1984: 285-288 i 1998: 559-566). 
rar-ne l'oratòria. ${ }^{20}$ Com hem vist, el Valeri havia de fortificar la ciutat en els valors polítics en paga de l'afecte que Barcelona havia tributat a Pere d'Aragó. Ja havia passat una generació, i les cites d'alguns clàssics eren habituals en mans de secretaris i predicadors. Però una anècdota de Valeri Màxim (V.I, ext. I) il·lustra el Tractatus de l'infant Pere (c. 24), com una mostra antiga d'aquesta extensió de l'afició familiar a la història exemplar.

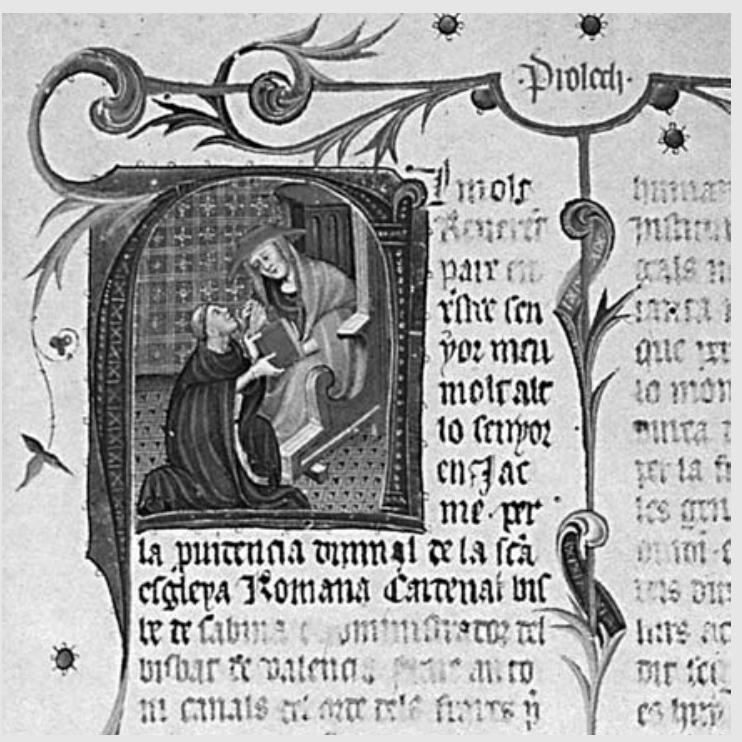

Detall de la miniatura inicial de la traducció del Valeri Màxim: fra Antoni Canals oferint l'obra al cardenal Jaume d'Aragó (Arxiu d'Història de la Ciutat de Barcelona).

\section{Política o història}

La decisió de fer-se franciscà en 1358, a banda els antecedents familiars i la visió de Falset, se solia justificar per la viudesa, que es creia molt recent. Alexandra Beauchamp (2005) ens ha fet saber que l'infant patia de poagre. Ara ens interessa només el resultat d'aquesta decisió meditada per mirar de fixar la literatura política de l'infant en el marc de la tradició. Tornem enrera.

Pere d'Aragó va ser un polític de gran influència i, sembla, oratòria contundent. En relació a Pere III, bastaria retreure el seu paper com a tutor del joveníssim rei en un moment particularment difícil, just a l'inici del regnat. Pere III ho va recordar a la Crònica.

20. Cátedra (1985-86: 35-36), i 31-36 per a l'ús de Valeri Màxim.
L'infant Pere s'oposava a la guerra amb Castella, previsible conseqüència de l'enfrontament entre el nou rei i la seva madrastra Leonor. En un Parlament celebrat el 1337 pren la paraula el cèlebre infant castellà don Juan Manuel, que buscava suport per fer la guerra al seu propi rei. Pere III escriu: «guardam lo dit infant En Pere, així com aquell qui era antic de la Casa d'Aragó, esperant que d'ell isqués la resposta necessària a açò». L'infant intervé:

Don Manuel, vós sots mon cunyat e mon amic, mas per tot açò no estaré que no consell a mon senyor lo rei ço que sia honor de la sua Corona, guardant de tot damnatge ell e tots sos regnes, e dic-vos que, si a mi creu, no us farà valença alguna, ne metrà, ne farà guerra per vós ab lo rei de Castella, e aquell consell que vós daríets al rei de Castella, vostre senyor, vull jo dar al dit rei, mon senyor. (Crònica, II, 27)

Al dubte expectant del rei, segueix una resposta fulgurant: concessió amistosa, adversativa, declaració sense ambigüitats i atac que talla la rèplica per preterició la fidelitat de l'infant Pere hauria de ser un model per a don Juan Manuel, i, si no fos així, és que aquest és un traïdor, algú de qui no et pots refiar en qualsevol cas. «E, dites aquestes paraules, lo dit Consell se llevà e res no s'hi parlà pus. E lo dit Joan Manuel, veent que son fet no havia Iloc, partîs de nós e anà-se'n en Castella».

Aquest escena marca el principi de la influència política de Pere d'Aragó sobre el seu nebot, arrabassat així de l'ambient aragonès que l'havia protegit. Uns vint anys després, el Tractatus de vita et moribus et regimine principum sive Comentarius in primum librum Regum, dedicat a Pere III, sembla, en feliç expressió del seu editor, el «testament polític» de l'infant. ${ }^{21}$ Només en conservem una còpia del segle XVIII, però feta sobre un manuscrit de presentació, en pergamí, luxós i il·luminat, que mostrava l'infant agenollat oferint el tractat al rei. La data post quem és un esment a la campanya de Pere III a Sardenya (1 354-55); el terme ante quem semblaria l'ingrés a l'orde franciscà, ja que l'infant encara exhibeix els títols als quals va renunciar. Ara, el jesuïta que va

21.Valls i Taberner (1926: 37, 286). Per a la interpretació política, vegeu ara Beauchamps (2005) que integra els suggeriments de Francesco Santi. El lector hi trobarà una sòlida argumentació per a més d'una de les observacions que segueixen, bé que no sempre amb la mateixa conclusió. 
copiar el text abans de regalar el manuscrit (perdut des de llavors) a don José Carvajal y Lancaster, va reproduir la miniatura inicial, precisant que Pere d'Aragó hi vestia I'hàbit franciscà. ${ }^{22}$ Sembla raonablement segur que el Tractatus es va redactar uns mesos abans de l'ingrés, potser amb pressa, i que l'oncle l'havia d'entendre com una ofrena cerimoniosa al nebot.

Costa creure, amb tot, que el Tractatus fos simplement honorífic, atesa la talla política de l'autor i la seva implicació en afers del segle encara després de l'ingrés a l'orde, i també costa pensar que no reflectís de cap manera el context històric immediat. L'infant va fer-se franciscà en un moment conflictiu, en plena campanya contra el rei de Castella — un any abans comandava les tropes en la defensa del regne de València. S'ha insinuat, dubtosament, que havia perdut poder, paral·lelament a l'ascensió de Bernat de Cabrera. ${ }^{23}$ Potser és millor recordar la malaltia i la seva oposició inicial a la guerra, segons la correspondència mantinguda amb el rei el febrer de 1357, coincidint amb l'arribada a Saragossa del legat papal, el cardenal Guillaume de la Jugie, amb intenció d'establir la concòrdia. El 8 de febrer el rei, impacient per combatre Pedro el Cruel, demana a l'infant que hi acudeixi amb reforços valencians, tot i saber que el legat ja era a Carinyena (va arribar l'endemà). L'infant devia donar llargues: el Consell de València deia que es resistia a «reebre lo siti de lloctinent general». El motiu de fons es dedueix d'una carta reial del dia 24: entre molt diversos arguments de l'infant, destaca el temor que es perdi el regne de València, si ell i el seu fill l'abandonen. Pere III es va veure obligat a respondre a les al-legacions amb una invocació a la sang del llinatge («nos meravellam de vós, qui sots eixits d'aquella sang real») i a l'exemple dels avantpassats que van defensar la terra, i amb una justificació de les raons de la guerra contra Pedro el Cruel; però al capdavall va deixar que l'infant romangués (I de març). ${ }^{24}$ Les tre-

22. Pou (1996:506, n. 106): «Initio codicis manuscripti elegans haec imago est, qua Infans Regi librum offerens ceruleo FF. Minorum Conventualium (sic) cucullo, ut arbitror, indutus, cernitur. Multis praeterea pagella tota Apostolarum imaginibus, flosculis atque ornamentis alijs diversi coloris varigatur». Beauchamp (2005) dóna més informació, de primera mà, i precisa la redacció del tractat, present després a la biblioteca del rei Martí.

23. Gubern (I955: 4I-42 i 104-06, carta de I35I).

24. Arxiu de la Corona d'Aragó, Cancelleria, reg. I I49, ff. 6 I i 84r. La carta del 24 de febrer, a Gubern (1955: I39-I55). Al darrera hi havia les dificultats per finançar una guerra defensiva: Abadal (1987: 225-237). ves signades el maig per un any foren més aviat nominals. L'estiu de 1358 la guerra recomençava de ple. En l'endemig Pere III va haver de convocar corts per obtenir finançament, i l'infant hi va ajudar (Pou 1996: 504).

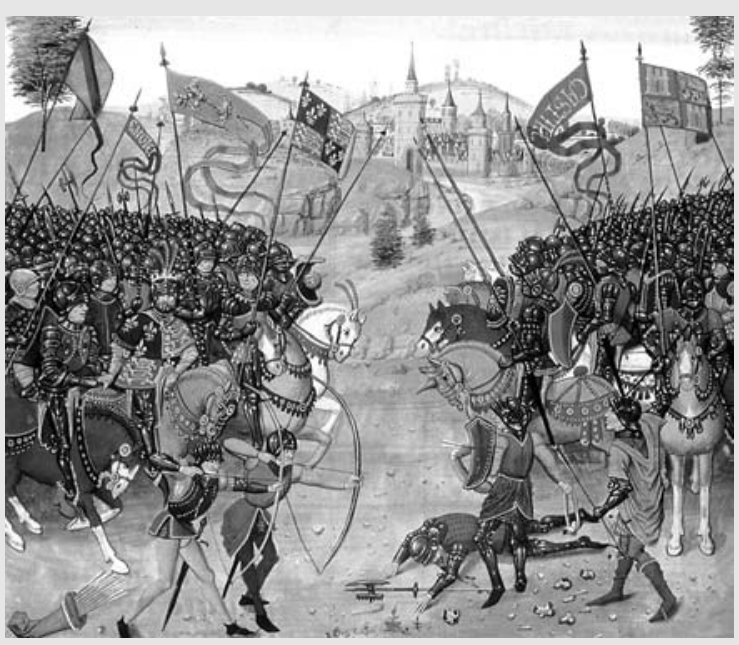

L'exèrcit de Pere el Cruel de Castella, enemic de Pedro el Cerimoniós, a punt d'entrar en combat contra el seu germà bastard Enric a Nájera (1367), en una miniatura de les cròniques de Jean Froissart (Biblioteca Nacional, París).

Seria del tot aventurat magnificar aquest conflicte d'interessos només pel fet que la raó política de l'infant coincidís, en un cert moment, amb la frustrada voluntat pacificadora d'InnocenciVI. Però em sembla una bona mostra de l'experiència real que deu bategar darrera el Tractatus. En tot cas, fra Pere dedica el capítol 24, excepcionalment dilatat, a les condicions d'una guerra justa: sempre, com hem vist més amunt, amb el consentiment de magnats i barons; mai per iniciativa personal (com va ser el cas de Pere III) ni per cap passió. L'altre moment en què s'aparta llargament de la pauta biblica és un parlament destinat a demostrar com el llinatge reial sempre ha vessat la pròpia sang al servei de l'Església (c. 8, comentat al següent epígraf).

El Tractatus és un comentari bíblic a alguns passatges del Primer llibre dels Reis ( I Sam |-16). En la història del pensament polític ha merescut poca atenció, arrelat com es troba en un món prearistotèlic; si de cas, s'hi ha observat l'espiritualisme franciscà que tenyeix l'obra de cap a cap. ${ }^{25}$ Les autoritats que va trenant l'autor, sagrades i patrístiques en general, no

25. Vegeu, per exemple, Carreras i Artau (200I: 524-525) i Elías de Tejada (1950: I24- | 30); i notem la rúbrica «De duabus vitis contemplativa et activa» (c. 9). Beauchamp (2005), en restitueix el valor. 
empenyen a buscar-hi gaire cosa més, si exceptuem una cita dels Aforismes d'Hipòcrates, seguida d'aquella de Valeri Màxim, i, sobretot, el recurs sovintejat al pseudo-aristotèlic Secretum secretorum (no a Aristòtil, com s'ha repetit a tort), un llibre que havia format part de l'educació de l'infant i que hem d'associar a la cultura del pare.

Aquesta aparent falta d'interès conceptual desapareix si llegim el Tractatus en el context de la literatura política més pròxima. ${ }^{26} \mathrm{~A}$ les cartes i parlaments del rei Pere, i a la mateixa Crònica, hi retrobem l'orientació bíblica. ${ }^{27}$ Aquest no és el Iloc per analitzar la tècnica exegètica de l'infant ni per establir relacions amb una oratòria tan influïda per la predicació com la de Pere III, però sí que hem d'observar algun tret de fons comú.

El llibre glossat al Tractatus és un text cabdal dels llibres històrics de l'Antic Testament: explica el naixement de la monarquia. L'infant l'aprofita amb aquesta intenció històrica: del pare de Samuel a aquest profeta; de Samuel a Saül, primer rei d'Israel; i de Saül, caigut en desgràcia per la supèrbia, a l'humil David. La perspectiva messiànica la donava la tradició de Llibres de fets reials des de ben antic: Jaume I, i el mateix llinatge, s'havien identificat amb Crist, com hem vist il·lustrat per Muntaner; ho confirmaria Desclot, quan compara l'entrada del futur Pere II a Sicília amb Moisès alliberant el poble del Faraó. David també prefigura Crist, aclamat a Jerusalem com a fill de (la casa de) David (Mt. 21:9). No estranya, doncs, que l'infant traci un recorregut des dels orígens (c. I) fins a la unció del rei-pastor (c. 35). L'origen es dilata de seguida per dibuixar, de la mà del profeta Daniel, la figura d'un príncep virtuosus i amb zelum Dei: per les virtuts cristianes personals, perquè reuneix oficials i súbdits en un cos i perquè està armat amb la justícia, el seny i la fe (c. I-8); llavors, saltant a la unció de Saül, l'autor justifica la institució de la monarquia, al·legant prosàpia i superioritat (c. 10), i s'adreça a Pere III per recordar-li el dia de la coronació (a la qual no havia volgut assistir!): la seva unció «per ministros Ecclesiae» i el deure de lluitar contra els enemics de la fe. D'altra banda, el final es prepara des del capítol 28 , amb insistència en el perill de la supèrbia. La lloança final exalta un David evangèlic i ecumènic, model de

\section{Ho deixa entendre Gubern (1955: 40-4I i 43).}

27. Per a la producció reial, vegeu Cátedra (1985-86), i la introducció a Hillgarth (1980: 4 I-43 i 76-82). Beauchamp (2005) ha tornat a posar de relleu els sermons de l'infant, encara per estudiar. futur, que no solament governi el poble d'Israel com un pastor fa pasturar el ramat, sinó que alimenti «totam Ecclesiam Dei» (c. 34); aquest ha de ser el patró perfecte del «nepos» caríssim (c. 35). En aquesta darrera secció, tan general, crida l'atenció el penúltim capítol («Quod princeps non debet esse vindicativus»): l'infant interpreta que David «mai no va desitjar venjar-se d'un enemic fidel», és a dir, de la mateixa fe. Com a sermó, anava ben encaminat: l'odi ferotge a Pedro el Cruel, ja excomunicat, potser no comptaria, però sí el cas de l'infant Jaume de Mallorca, tancat de nit en una gàbia al Castell Nou per expressa ordre reial d'aquell 1358.

El rei Pere, o els seus assessors, van recórrer sovint als Llibres dels Reis. El parlament de Montsó (1383), per exemple, es desplega a manera de sermó amb el thema de I Sa 3:6, i el de sant Mateu fa el mateix amb 2 Sa 15: I : en aquest, Absalon, fill traïdor a David, s'identifica amb al rebel Jutge d'Arborea (Albert \& Gassiot 1928: 52-56 i 33-42). No sobtarà, doncs, que a la introducció de la Crònica, dissenyada amb tècnica semblant, el rei es proposi directament «així com altre David» (Pròleg, 4). Si els textos parlessin entre ells, aquest seria una rèplica al Tractatus: aquí no hi ha un rex futurus i per a tota l'Església, sinó un que parla del passat i personalment, volent justificar sobretot la cadena de «guerres i tribulacions» mogudes per enemics de dins (Absalon, val a dir els propis vassalls) i de fora (com Pedro el Cruel). En comptes d'aquell pastor humil, incapaç de desitjar la mort de cap enemic si en compartia la fe, ara tenim un David del qual es va escriure «l'espasa no s'allunyarà mai de casa teva» (2 Sam 12: 10). Tota la violència (i, afegeixo, sovint la venjança) queda justificada pel providencialisme:

Per què podem nós dir ab David aquella paraula que és escrita $1^{\circ}$ Regum, XVII ${ }^{\circ}$ [ Sam 17:37]: «Dominus eripuit me de ore leonis et de mano ursì, com Déu nos ha delliurat de mà del rei de Castella, qui era lleó devorant per sa mala condició e propietat, e per son senyal, com en sa bandera fa lleó, e de mà de l'ors, qui és animal immunde e significa persones malicioses que per llur malícia se llevaren contra nós e nostre regne, dels quals la llarga bondat de Déu delliurà nós e nostra casa. (Crònica, Pròleg, 4). ${ }^{28}$

28. Corregeixo la referència a la cita bíblica, tal com fa Hillgarth (1980: 129 i n. 6). 
Pedro Cátedra ha trobat en Robert d'Anjou, el rei «da sermone», un possible model per a l'oratòria de Pere III, i ha destacat que l'infant Pere va educar-se en el mateix ambient franciscà que el seu oncle Robert (Cátedra 1985-86: 20-22). Recordem, per no allargar-nos, la visió de Falset, amb l'aparició de sant Lluís (d'Anjou). No gosaria dir que l'infant també va ser una influència de poca o molta importància, o que el Tractatus va deixar petja en els textos del rei Pere. Però almenys hem de concloure que fa sentit integrat en el corpus de la literatura política familiar. Vist així, i a banda les realitats històriques que s'hi vulguin detectar, aquest sentit es distingeix nítidament. Pere III vol deixar clar que la providència l'autoritza directament. Per a fra Pere d'Aragó, entre Déu i el rei, hi ha l'Església. ${ }^{29}$

\section{Oratòria}

Aquest lloc en la producció de la familia se li ha de retornar, sense dubte, a la llum del capítol 8 . De fet s'ha suggerit (ho deixa entendre Gubern 1955: 40-4I i 43; vegeu la nota 24), sobre aquest text, que l'infant va contribuir a desvetllar en el rei la veneració pels exemples dels antecessors. Fa de mal dir. No conservem parlaments d'abans de 1350 i la pràctica de citar els avantpassats ja estava estesa quan el rei escriu aquella carta de 1357 justificant la guerra. ${ }^{30} \mathrm{La}$ intenció final del capítol s'expressa a la rúbrica («De principe quod summe debet esse catholicus»). Tot seguit, unes poques ratlles d'exegesi biblica semblen el pretext per a un discurs del tot equivalent a fragments conservats de l'oratòria reial, ja fos a les corts o en arengues a les tropes (Crònica, VI, 40). En síntesi, l'oratòria de l'infant mostra com la prosàpia del rei, per la doble via catalana i aragonesa, sempre va actuar seguint l'obediència de l'Església, i això fins a l'heroisme i el martiri.

Comença amb una pregunta retòrica: «Va haver-hi mai a l'Aragó un rei o un príncep que, per aquesta fe catòlica, no morís o no es banyés en la seva pròpia sang?» ( Quis unquam fuit rex vel princeps in Aragonia qui non

\footnotetext{
29. Beauchamp (2005) interpreta el Tractatus com un recull de consells pràctics per al rei, en el difícil moment de la guerra: no hi hauria distància crítica, sinó un recordatori sobre com revestir-se de l'autoritat necessària.
}

30. Hillgarth (1980:80), retreu una lletra similar de Bernat de Cabrera (I348), parafrasejada per Zurita. sit pro hac Fide Catholica mortuus, aut proprio sanguine lotus?»)). A continuació, es reciten gestes d'Alfons III, Jaume II i Jaume I; després, dels reis d'Aragó abans de la Unió (Sancho III, conegut com a Sancho Ramírez, i el seu fill Alfonso I, «dictus bellator») i de Sanç d'Aragó, fill petit de Jaume I. Finalment, li toca el torn al mateix Pere III. Observem la saviesa de la disposició. Primer vénen els catalans, tots tres ferits en combat (cf. «aut proprio sanguine lotus»), en ordre ascendent: el pare («pater tuo»), l'avi («avus tuus paterque meus») i el rebesavi («abavo tuo») del rei Pere. Després descendeixen els aragonesos, amb l'afegit de Sanç, arquebisbe de Toledo, tots tres morts (cf. «mortuus») Iluitant contra els infidels: Sancho Ramírez al setge d'Osca (1094) i el Bataller a Fraga ( I 134), com deia la tradició llegendària, i l'arquebisbe a Jaén (1275). Notem també la posició inicial dels catalans i la voluntat d'integrar-hi els aragonesos, presents naturalment en la perspectiva de la Crònica general que en aquells anys dirigia el rei Pere. ${ }^{31}$

La segona terna, amb comentari escarit, no demana gaire justificació: els tres predecessors són màrtirs de la fe. Les tres primeres anècdotes, en canvi, estan molt més elaborades i denoten una tria acurada i doncs un coneixement de primera mà de la història familiar, per via oral o d'arxiu. D'Alfons, per exemple, se'n recorda un fet conegudíssim: la victòria contra els pisans al camp de Lucocisterna, per Quaresma de 1324, durant la conquesta de Sardenya. L'infant de seguida deixa clar que la campanya es feia a precs de l'Església (cf. Crònica, I, I2), i que l'infant Alfons s'hi va comportar «com un altre Judes Macabeu», massacrant amb l'espasa l'enemic. Alguns detalls del relat coincideixen més aviat amb la versió de Muntaner (cap. 275): fra Pere explica com els enemics trien Alfons com a objectiu, com cau a terra ferit però s'esforça i, redreçat pels fidels, obté la victòria amb l'ajuda divina. Ara, hi ha un detall a la Crònica de Pere III molt significatiu: «en lo camp qui és dit Lucisterna, apella[n]t 'l'Ajutori de Nostre Senyor Déus', la davantera ferí» (I, 42). ${ }^{32}$ Aquest és el sant i senya de

\footnotetext{
31. Soberanas (1961: 63, c. 17; 67, c. 19 i 1 18, c. 35). L'infant recull la llegenda de la mort d'Alfonso I a Fraga, però no la coneguda variant segons la qual va desaparèixer; li convé mort: «in bello sarracenorum occubuit.» Per a la invocació als reis ante unionem, vegeu també el parlament de Pere III a Tarragona (Albert \& Gassiot 1928: 47-48) i el de Martí I a Saragossa (Cátedra 1985-86: 4I), potser deutor de la Crònica general.
}

32. Cortadellas (1995: 42). Hi he corregit «apellat», d'acord amb Hillgarth (1980: 159). 
Judes Macabeu en la batalla contra Nicànor («et dato signo adiutorii Dei»; 2 Mac 8:23). Això vol dir, crec, que l'infant recollia una tradició interna que havia establert una lectura providencialista de la victòria, les traces de la qual es retroben a la Crònica del seu nebot.

Pere III va presentar el seu pare com un heroi cavalleresc, lluitant «com a lleó i bon cavaller», amb «denou colps d'espasa» a la gorgera i brandant la famosa espasa Vilardell (I 42; vegeu Riquer 2000: I22- I23). L'infant passa per alt l'espasa de virtut, i tampoc posa èmfasi en l'heroisme dels cavallers, esmentats nominalment per Muntaner i Pere III (i repetidament recordats en adreces als súbdits fins a Martí l'Humà), ni diu res de la recuperació de la senyera: el seu heroi, més que un cavaller o un patriota, era, sobretot, un rei al servei de Déu. No tant un rei de propaganda èpica, com un rei legitimat.

Tractaré més per sobre les dues anècdotes restants. La primera presenta a Jaume II vencent el seu germà Frederic de Sicilia a la batalla naval de Cap d'Orlando (juliol 1299) i assaltant personalment el castell de Milazzo: en tots dos casos fou ferit per tret de sageta, al peu — precisa - en el combat naval. ${ }^{33}$ L'infant s'exclama: «O inestimabile et admirabile fidei et obedientie bonum!» Obediència al papa, glosso, perquè Jaume, en virtut del tractat d'Anagni, havia abandonat Sicilia («Regnum dimisit Siciliae») per desig del pontífex, i per sol-licitud papal havia lluitat (a contracor, segons alguna versió) contra el seu propi germà, «el qual estimava tendríssimament», postil la fra Pere. ${ }^{34}$ L'escena sobre «el rei Jaume l'antic», oberta amb una apel·lació a l'audiència («audiant qui non norunt»), ens porta al setge de Borriana. Segons l'infant, una nit, vigilant els seus «com un bon pastor cuida el seu ramat», Jaume I es va acostar tant a la muralla que una fletxa el va ferir al costat. En aquest cas l'accent cau en la conquesta del regne de València, un dels que va arrencar de «la gola dels pagans», i en la figura evangèlica del Bon pastor.

\footnotetext{
33. La Crònica general ho explica amb més èpica: «En la qual batalla lo dit rei En Jacme fo ferit ab passador per lo peu qui el cosí ab la coberta de la galea. E mentre durà la batalla, sol no moc lo peu ni féu aparès que fos nafrat, de la qual cosa tot hom se donà gran meravella» (Soberanas 196I: 165). Jaume II relata la batalla al papa sense esmentar les ferides, però un seu legat a la cúria recorda: «et de la mort, senyor, sots estat vós ben a prop algunes vegades» (Finke 1908: 57-58 i 61-62).
}

34. Vegeu el resum de Ferran Soldevila (1962: 393-400).

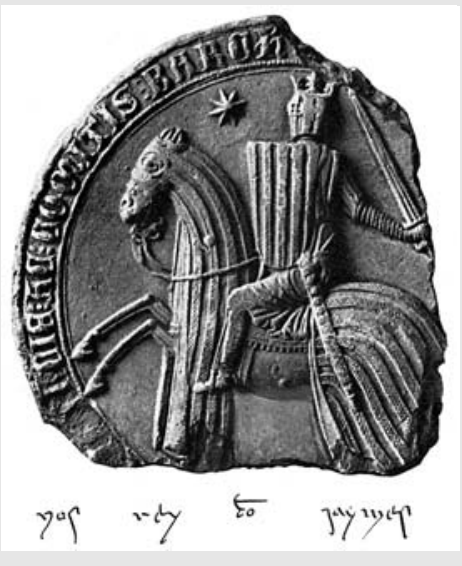

Jaume II representat com a batallador al seu segell.
Finalment, passats els tres màrtirs, Pere s'adreça al seu nebot per recordar-li la campanya de Sardenya, empresa per defensar l'Església i la Corona, puntualitza. No pot evocar cap ferida, però sí la malaltia que va dur Pere III a les portes de la mort durant el setge de l'Alguer, l'estiu de 1354. Naturalment, la Crònica no en diu res, perquè el rei, volent amagar els estralls del paludisme, havia insistit en el «bon aire» de l'illa, per carta i fins i tot enviant un sirventès al seu oncle i lloctinent. La realitat, però, l'infant la coneixia a la perfecció. ${ }^{35}$ L'altre element implícit, crec, és la debilitat física de Pere III. Per tot això l'infant reprodueix unes paraules que va pronunciar el seu nebot («quod audivi ab ore tuo») durant una conversa mantinguda mentre es feien els preparatius per a l'expedició. L'infant desaconsellava amb múltiples arguments el viatge reial a causa del perill imminent «persone tue». Podia fer-ho, «amb reverència deguda», és clar, perquè era el membre més antic del Consell que havia aprovat la campanya (Crònica, V, 30). ${ }^{36}$ Ara no es retreu la discussió sinó la resposta: el rei va dir que no hi deixaria d'anar ni que sabés del cert que hi havia de morir, que pels afers de l'Església i la defensa dels regnes «lucrum erat ('era un guany') mori et vivere Christo». Foren, conclou l'infant, «paraules notables i dignes de memòria»: la memòria que Pere d'Aragó va preservar amb pàgines com aquestes, també dignes de ser recordades com un exemple de bona oratòria; la memòria que donava un sentit polític a la història de la seva família.

35. Vegeu Cifuentes \& García Ballester (1990: esp. 193-195 i doc. 6).

36. Amb l'estol ja gairebé a punt, el rebel Jutge d'Arborea va oferir un acord, rebutjat pel rei, que incloïa lliurar-se ell mateix a l'infant Pere en cas d'incompliment (Crònica,V, 34). 


\section{Bibliografia}

ABADAL, Ramon d', 1987: Pere el

Cerimoniós i els inicis de la decadència política a Catalunya, Barcelona: Edicions 62

Albert, Ricard i Joan GASSIOT, 1928 : Parlaments a les corts catalanes, Barcelona: Barcino.

Alfons Maria de Barcelona, 1913-15: «El infante fray Pedro de Aragón», Estudios Franciscanos, I I, 1913: 13236; I2, 19|4: |29-4|, 434-38; I3, 19|4: 204-15; 14, 1915: 205-18; i 15, 1915: 58-65.

BADIA, Lola, 1983: Poesia catalana del segle XIV: edició $i$ estudi del "Cançoneret de Ripoll», Barcelona: Quaderns Crema.

BEAUCHAMP, Alexandra, 2005: «De l'action à l'écriture: le De regimine principum de l'infant Pierre d'Aragon», Anuario de Estudios Medievales, 35, 233-270, en premsa.

BoHIgAs, Pere, 1923: «Profecies catalanes dels segles XIV i XV: assaig bibliogràfic»), Butlletí de la Biblioteca de Catalunya, 6: 24-49.

CABRÉ, Lluís, 1993: Pere March, Obra completa, Barcelona: Barcino.

Carreras I Artau, Tomàs i Joaquim, 200I: Història de la filosofia espanyola, II, Filosofia cristiana del segle XIII al XV, edició facsímil, Barcelona-Girona: IEC-Diputació de Girona.

CASACUBERTA, J.M, I 927-52: Ramon Muntaner Crònica, ed. E. B. [Casacuberta, J. M. de], revisada per M. Coll i Alentorn, Barcelona: Barcino.

CASAS Homs, Josep M. (ed), 1969: Joan de Castellnou, Obres en prosa (segle XIV), Barcelona: Fundació Salvador Vives Casajoana.

CÁtedra, Pedro, 1985-86: «Acerca del sermón político en la España medieval», Boletín de la Real
Academia de Buenas Letras de Barcelona, 40, 17-47.

\section{Cifuentes, Lluís i Luis García} BALLESTER, 1990: «Els professionals sanitaris de la Corona d'Aragó en l'expedició militar a Sardenya de |354-55», Arxiu de Textos Catalans Antics, 9, |83-2|4.

Cortadellas, Anna (ed), 1995: Pere III el Cerimoniós, Crònica, amb pròleg de J.N. Hillgarth, Barcelona: Edicions 62.

ElíAS de TejadA, Francisco, 1950: Las doctrinas políticas en la Cataluña medieval, Barcelona:Aymà.

EsPADAler, Anton Maria, 200I: «La Catalogna dei re», Lo spazio letterario del medioevo, 2: II medioevo volgare, I: La produzione del testo, II, ed. Piero Boitani et al., Roma, Salerno Editrice, 873-933.

FINKE, Heinrich, 1908: Acta Aragonensia, I, Berlín i Leipzig:Walter Rothschild.

Gubern, Ramon, 1955: Epistolari de Pere III, I, Barcelona: Barcino.

HaUf, Albert, 1990: D’Eiximenis a Sor Isabel de Villena, Barcelona: IFV i PAM.

HillgarTh, J.N. (ed), 1980: Pere III of Catalonia, Chronicle, tr. Mary Hillgarth, Toronto: Pontifical Institute of Mediaeval Studies. Traducció catalana del pròleg, a cura de Miriam Cabré i Maria Toldrà, a Llengua \& Literatura, 5 (1992-93), 7-102.

LeE, Harold, Marjorie ReEves i Giulio SILANO, 1989: Western Mediterranean Prophecy:The School of Joachim de Fiore and the Fourteenth-Century Breviloquium, Toronto: Pontifical Institute of Mediaeval Studies.

Marshall, J. H., 1972: The «Razos de trobar» of Raimon Vidal and
Associated Texts, Londres: Oxford University Press.

Martí de Barcelona, 1990-91: «La cultura catalana durant el regnat de Jaume II», Estudios Franciscanos, 91, 1990: 213-295 i 92, 1991: 127-245 i 383-492.

Martínez Ferrando, J. Ernest, 1948: Jaime II de Aragón: su vida familiar, I, Barcelona: CSIC.

McVaugh, Michael, 1986: «The Births of the Children of Jaime II»), Medievalia, 6: 7-I6.

MIOUEL y Planas, Ramon, 1914: Llibre anomenat Valeri Màximo, Barcelona.

POU I MARTí, Josep, 1996: Visionarios, beguinos y fraticelos catalanes (siglos XIII-XV) (1930), ed.Albert Hauf i Valls, Alacant: Instituto de Cultura Juan Gil Albert i Diputación Provincial.

PujOL, Josep, 1991: «Unes cobles inèdites de Jacme March» Els Marges, 44, 5I-60.

PujOL, Josep, 1994: Jaume March Obro poètica, Barcelona: Barcino.

Rıco, Francisco, 1984: «Antoni Canals y Petrarca: para la fecha y las fuentes de Scipió e Aníbal», Estudios en memoria del profesor Manuel SanchisGuarner, I, València: Universidad.

Rıco, Francisco, 1998: «Nobiltà del Medioevo, nobiltà dell'Umanesimo», a Gli umanesimi medievali.Atti del II Congresso dell'Internationales Mittellateinerkomitee, ed. Claudio Leonardi, Florència: SISMEL Edizioni del Galluzzo.

RIQUeR, Martí de, 1964: Història de la literatura catalana, II, Barcelona:Ariel.

RIQUeR, Martí de, 2000: Llegendes històriques catalanes, Barcelona: Quaderns Crema. 
RUBIÓ I LLUCH,Antoni, 1921: Documents per l'historia de la cultura catalana mig-eval, II, Barcelona: Institut d'Estudis Catalans.

SÁNCHEZ-CUTILLAS, Carmelina, 1967: Lletres closes de Pere el Cerimoniós endreçades al Consell de València, Barcelona: Rafael Dalmau.

SOBERANAS, Amadeu-J., 196I: Crònica general de Pere el Cerimoniós dita comunament Crònica de Sant Joan de la Penya, Barcelona:Alpha.
SOBREQUÉs, Santiago, 1957: Els barons de Catalunya, Barcelona:Vicens Vives.

SOLDEVILA, Ferran, 1962: Història de Catalunya, 2a ed. Barcelona:Alpha.

TASIS I MARCA, Rafael, 1957: Pere el Cerimoniós i els seus fills, Barcelona: Vicens-Vives.

VALLS I TABERNER, Ferran, 1926: «EI tractat De regimine principum de l'infant Pere d'Aragó», Estudis franciscans, 37, 27I-287 i 432-450; i 38, $107-119$ i 192-209.
VARVARO,Alberto, I984: «Il testo storiografico come opera letteraria: Ramon Muntaner», Symposium in honorem prof. M. de Riquer, Barcelona: Quaderns Crema i Universitat, 403-4I5.

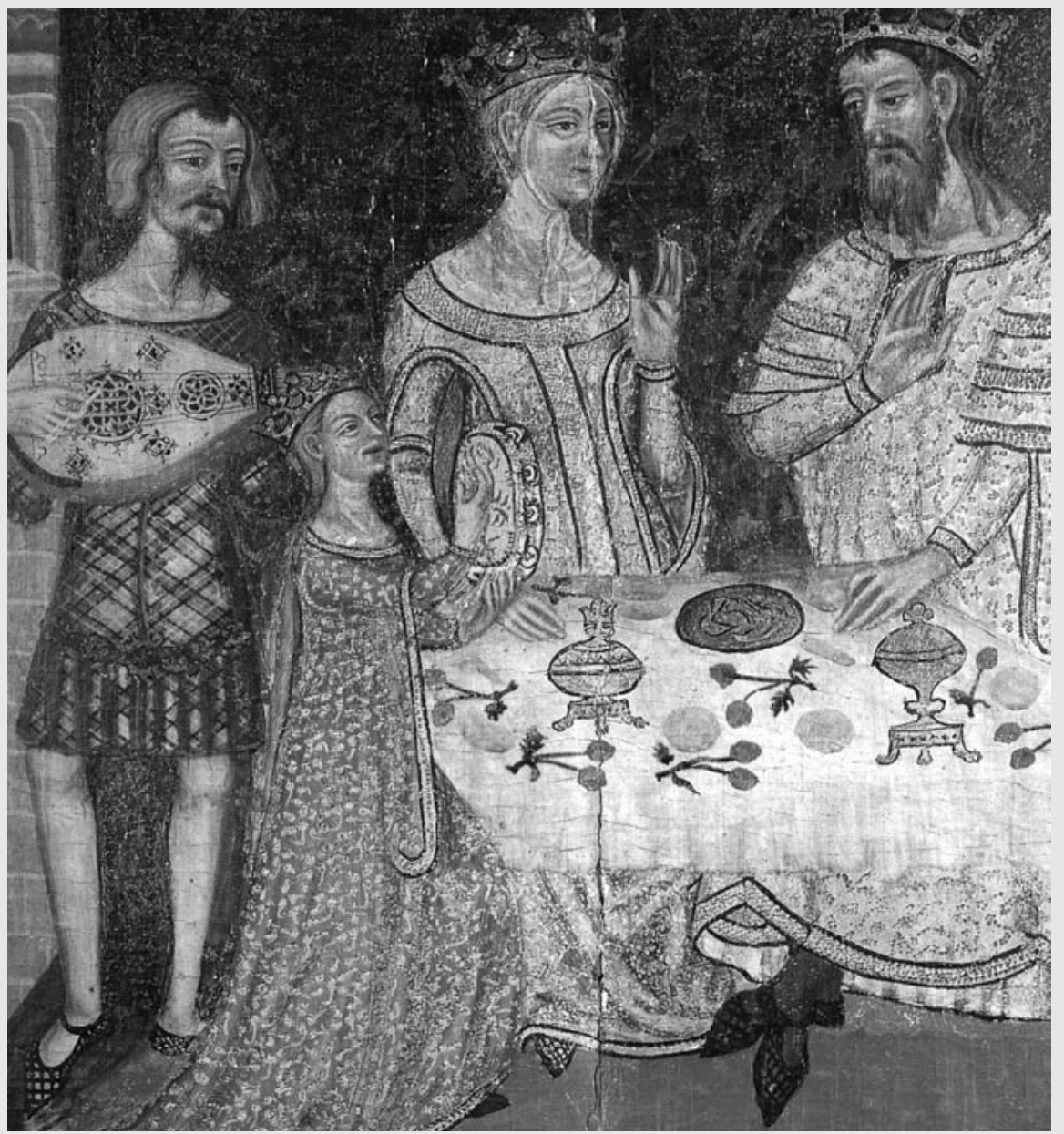

Per a aquesta escena de banquet, sembla que el mestre de Santa Coloma de Queralt (c. 1356) es va inspirar en la cort de Pere el Cerimoniós i Elionor de Sicília (MNAC, Barcelona). 


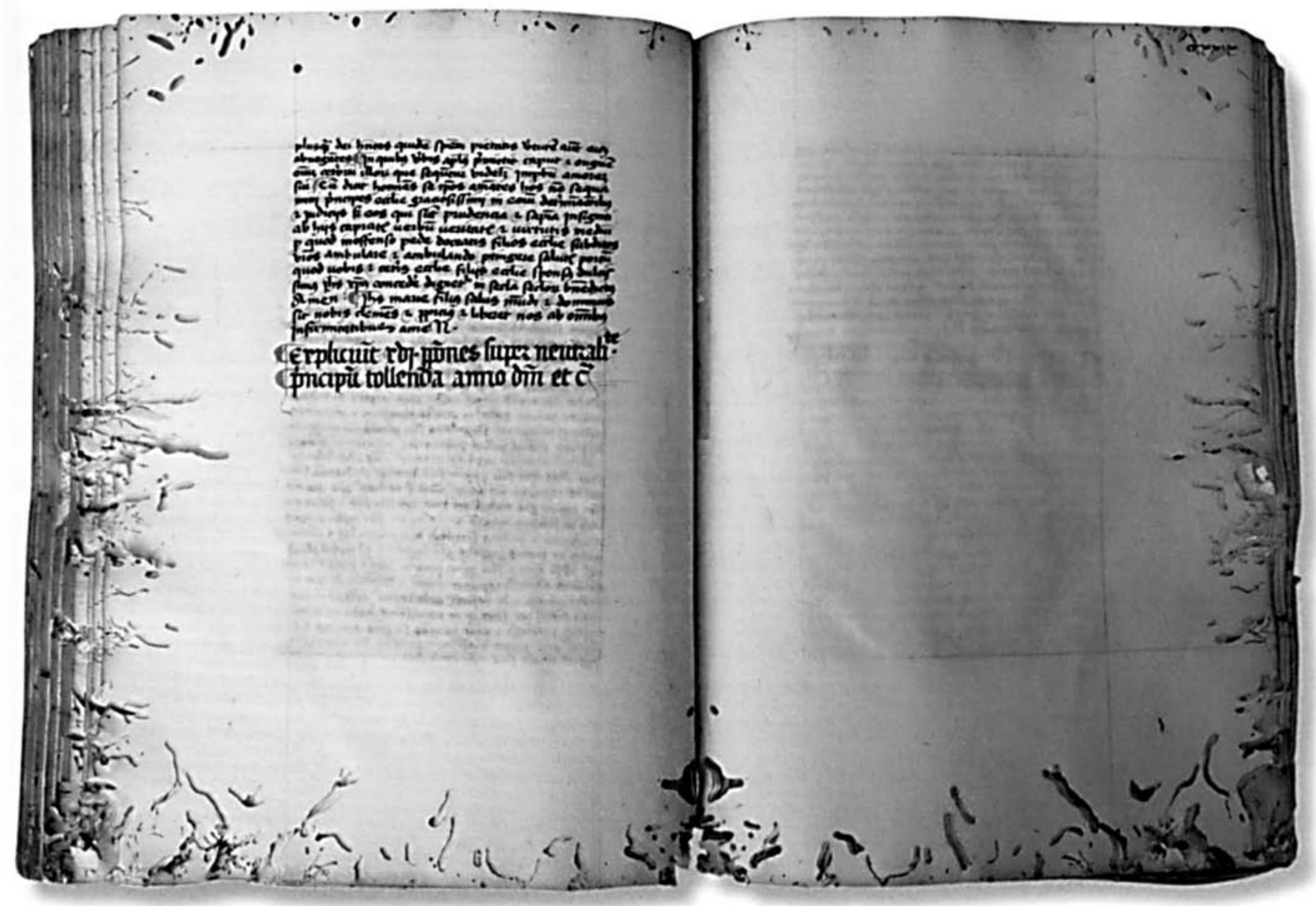

